\title{
Purine Analogs Inhibit Nerve Growth Factor-Promoted Neurite Outgrowth by Sympathetic and Sensory Neurons
}

\author{
Lloyd A. Greene, ${ }^{1}$ Cinzia Volonté, ${ }^{1}$ and Alcmène Chalazonitis ${ }^{2}$ \\ 'Department of Pathology and Center for Neurobiology and Behavior, Columbia University College of Physicians and \\ Surgeons, New York, New York 10032, and 'Department of Neuroscience, Albert Einstein College of Medicine, Bronx, \\ New York 10461
}

\begin{abstract}
Past studies have shown that purine analogs block certain, but not all, responses of cultured rat PC12 pheochromocytoma cells to nerve growth factor (NGF). In the present work, newborn rat sympathetic and sensory neurons were exposed to NGF in the presence or absence of the purine analogs 6-thioguanine and 2-aminopurine. These compounds reversibly suppressed NGF-dependent neurite outgrowth by the neurons and did so at concentrations comparable to those effective on PC12 cells. In contrast to their effects on neurites, neither compound significantly blocked NGF-promoted neuronal survival. Similar effects were seen with cultures of chick embryo sympathetic ganglia. These findings show that purine analog effects on NGF responses can be extended to mammalian and avian neurons. Moreover, the differential effects of the analogs on neurite outgrowth and survival indicate that these 2 actions of NGF can be dissected from one another and may represent different mechanistic pathways.
\end{abstract}

One of the more intriguing aspects of neurotrophic proteins such as nerve growth factor (NGF) is that a single agent can elicit so wide a variety of responses from its target cells (Levi-Montalcini, 1987). This raises the issue as to whether a single mechanistic pathway is involved or whether there are parallel or divergent pathways of action. To address this, we have sought to develop means that might dissect the various effects of NGF from one another. In this regard, we have reported that purine analogs can differentially block some, but not other, actions of NGF on the rat PC12 pheochromocytoma cell line (Volonté et al., 1989). For instance, purine analogs suppressed NGF-promoted neurite regeneration and induction of ornithine decarboxylase activity in $\mathrm{PC} 12$ cell cultures but did not block certain rapid NGFelicited changes in protein phosphorylation, including that of microtubule-associated protein 1.2 (MAP 1.2). We also noted differences among the effects of purine analogs. Most, exemplified by 2 -aminopurine (2-AP), were effective in the $1-10 \mathrm{~mm}$ range. In contrast, 6-thioguanine (6-TG) was effective in the range of about $1-10 \mu \mathrm{M}$. Furthermore, 2-AP blocked the NGF-

\footnotetext{
Received Sept. 18, 1989; revised Nov. 14, 1989; accepted Nov. 15, 1989.

This work was supported by grants NS16036 and NS27680 from the USPHS. We thank Dr. Lorna Role for providing E11 chick embryos and Dr. John Kessler for generously permitting the use of his cell culture facilities for a portion of these experiments.

Correspondence should be addressed to Lloyd A. Greene, Department of Pathology, Columbia University College of Physicians and Surgeons, $630 \mathrm{~W}$. 168 th Street, New York, NY 10032.

Copyright (C) 1990 Society for Neuroscience $0270-6474 / 90 / 051479-07 \$ 02.00 / 0$
}

promoted induction of $c-f \circ s \mathrm{mRNA}$ and the activation of a specific protein kinase activity (protein kinase $\mathrm{N}$ ), whereas 6-TG, even at high concentrations, did not.

The present study has several aims. The first has been to determine whether purine analog actions can be extended from PC12 cells to their homologs-sympathetic neurons. A second aim has been to test whether the analogs affect another class of NGF-responsive neurons, namely, sensory neurons, and whether they are also effective in species other than mammals. A third aim has been to continue to use purine analogs to dissect NGF actions from one another. In particular, cultured sympathetic and sensory neurons not only undergo NGF-stimulated neurite outgrowth, but, unlike proliferating PC12 cells (Greene and Tischler, 1976), show a strong dependence on NGF for survival (Levi-Montalcini and Angeletti, 1963; Varon et al., 1973; Chun and Patterson, 1977; Barde et al., 1980). They are therefore suitable for determining whether promotion of survival and of neurite outgrowth can be mechanistically separated from one another.

\section{Materials and Methods}

Cell culture. Dissociated cell cultures of newborn rat superior cervical sympathetic ganglia and of E1 1 chick embryo paravertebral sympathetic ganglia were prepared and maintained as previously described (Greene, 1977; Lee et al., 1981) in $35 \mathrm{~mm}$ tissue culture dishes coated with rat tail collagen. Cultures of newborn rat dissociated dorsal root ganglia (DRG) were prepared according to previously published procedures (Chalazonitis and Fischbach, 1980; Adler et al., 1984) and were maintained in $35 \mathrm{~mm}$ dishes coated with collagen and laminin $(10 \mu \mathrm{g} / \mathrm{ml})$ in EMEM medium supplemented with $10 \%$ horse serum but without chick embryo extract or fetal bovine serum. Plating densities were $1-2,15-$ 20 , and 10-15 ganglia per dish for rat sympathetic, rat dorsal root, and chick sympathetic ganglia, respectively. Where specified, the culture media contained $50 \mathrm{ng} / \mathrm{ml}(2 \mathrm{nM})$ mouse submaxillary gland NGF and the indicated concentrations of 6-thioguanine or 2-aminopurine (Sigma Chemical). The latter were prepared from stock solutions ( 5 and 100 $\mathrm{mM}$, respectively) in culture medium without serum (Volonté et al., 1989).

Assessment of neuronal number and neurite outgrowth. For sympathetic neuron cultures, diametric strips (each corresponding to about $10 \%$ of the total surface area of the dish) were examined under highpower phase-contrast optics. Counts were made of the number of cells with neuron-like morphology (round, phase-bright with prominent nucleoli) and of the number of such cells bearing neurites. Special care was taken to assure that the processes could be traced back to the soma and did not originate from associated Schwann cells. When NGF was present, approximately 700-1500 neurons were scored per culture. Similar techniques were employed in evaluating the DRG cultures except that 20 fields on 2 orthogonal axes per culture were examined at $200 \times$ magnification for counting and at $1000 \times$ for tracing processes back to neuronal perikarya. 

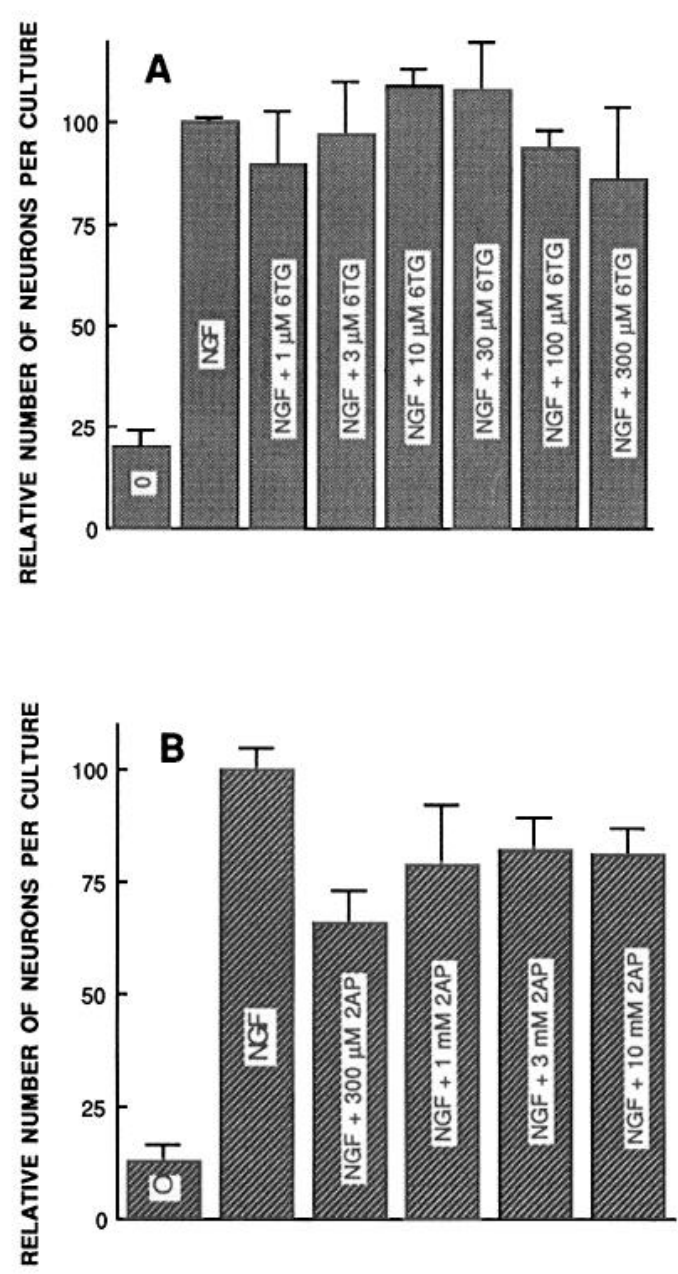

Figure 1. Effects of various concentrations of 6-thioguanine (6-TG) and 2-aminopurine (2-AP) on the NGF-promoted survival of newborn rat superior cervical sympathetic ganglion neurons in culture. Replicate cultures were plated with or without NGF or with NGF and the indicated concentrations of 6-TG $(A)$ or 2-AP $(B)$. Numbers of surviving neurons were assessed at approximately $24 \mathrm{hr}$ after plating. Values are reported relative to the average number of neurons per dish for cultures receiving NGF alone $(21,168$ in $A, 17,938$ in $B)$ and represent the average of counts on duplicate cultures. Error bars indicate the range of the 2 values per condition. Comparable results were achieved in a replicate experiment.

\section{Results}

Dissociated newborn rat sympathetic ganglion cells were plated with or without NGF and in the presence or absence of various concentrations of the purine analogs 6-TG and 2-AP. In agreement with previous findings, NGF strongly promoted neuron survival so that few neurons survived without NGF even 1 day following plating (Fig. 1). The data in Figure $1 A$ show that the presence of 6-TG at up to $300 \mu \mathrm{M}$ did not substantially alter the ability of NGF to promote neuron survival. A small degree of toxicity was observed with 2-AP and NGF, but neuronal survival at up to $10 \mathrm{~mm}$ 2-AP plus NGF was far higher than in the absence of NGF (Fig. 1B). The analogs did not promote neuron survival when administered in the absence of NGF (data not shown). In contrast, both 6-TG and 2-AP did affect NGFpromoted neurite outgrowth. The dose-response data given in Figure 2 show that 6-TG and 2-AP suppressed neurite outgrowth, with $\mathrm{IC}_{50}$ values of about $7 \mu \mathrm{M}$ and $3 \mathrm{mM}$, respectively.

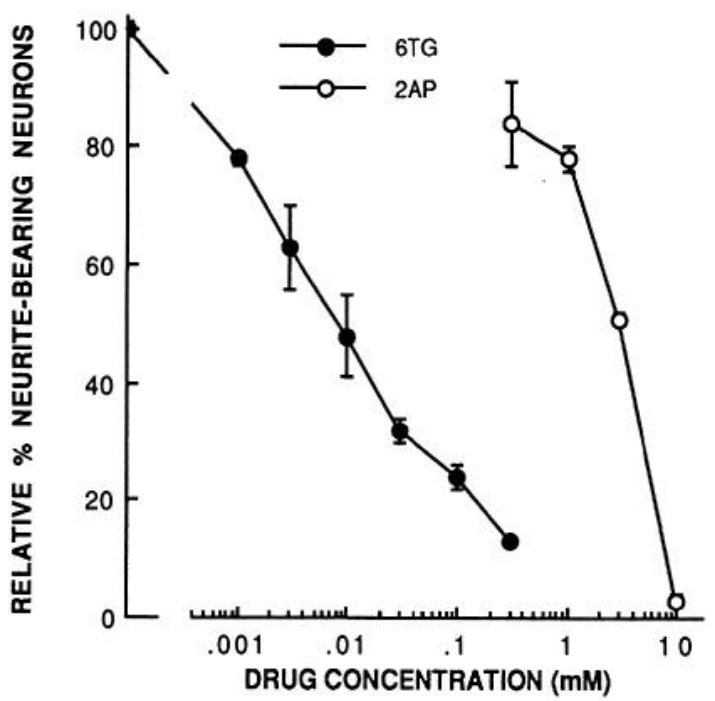

Figure 2. Dose-response relationship for the effect of 6-TG (filled circles) and 2-AP (open circles) on NGF-promoted neurite outgrowth by cultured newborn rat sympathetic ganglion neurons. Data were derived from the same set of cultures described in the legend to Figure 1. Values were normalized so that 100 represents the average percentage of neurite-bearing neurons in cultures maintained with NGF. The actual value of the latter was $82.5 \%$ for the experiment with $6-\mathrm{TG}$ and $89 \%$ for the experiment with 2-AP. Error bars indicate the range of values from duplicate cultures for each condition. Comparable results were achieved in a replicate experiment for each drug.

The effects of the purine analogs on cell morphology are illustrated in Figure 3 and reveal apparently healthy-looking cell bodies that do not bear processes. The integrity of the purinetreated cells is further substantiated by the observation that washout of either 6-TG or 2-AP resulted in the outgrowth of neurites (Fig. 4). With continuous exposure to the analogs, neurite outgrowth remained suppressed; however, after 3-4 d, the cell bodies began to show signs of deterioration and by 4-6 $d$ of treatment, cell death was apparent.

To determine whether the effects of the purine analogs extend to NGF-responsive cells in addition to sympathetic neurons, newborn rat dorsal root ganglionic cultures were also examined. At $1 \mathrm{~d}$ after plating, NGF increased the number of surviving DRG neurons by about $30-40 \%$ (Fig. 5, $A, C$ ); this effect on survival was not blocked by levels of 6-TG $(300 \mu \mathrm{M})$ or 2-AP $(10 \mathrm{~mm})$ that effectively suppressed neurite outgrowth in rat sympathetic neuron cultures (Fig. 5). NGF also increased the proportion of DRG neurons with neurites by 4-5-fold. In contrast to their effects on survival, both 6-TG and 2-AP suppressed this outgrowth (Figs. 5, 6). As illustrated in Figure 6, the effect of the purine analogs on neurite outgrowth was, as in the case of sympathetic neurons, reversible.

Experiments were carried out to observe whether the effects of purine analogs on NGF-promoted neurite outgrowth could be extended across species. Cultures of dissociated E11 chick embryo sympathetic ganglia were exposed to NGF in the absence or presence of various concentrations of 6-TG or 2-AP. After $1 \mathrm{~d}$, the cultures were assessed for neuron number and proportion of neurite-bearing cells. The data in Figure 7 indicate that neither analog significantly affected NGF-promoted survival, but that both effectively inhibited neurite outgrowth. The effective concentrations of the compounds were very similar to those observed for rat sympathetic neurons (Fig. 2). 

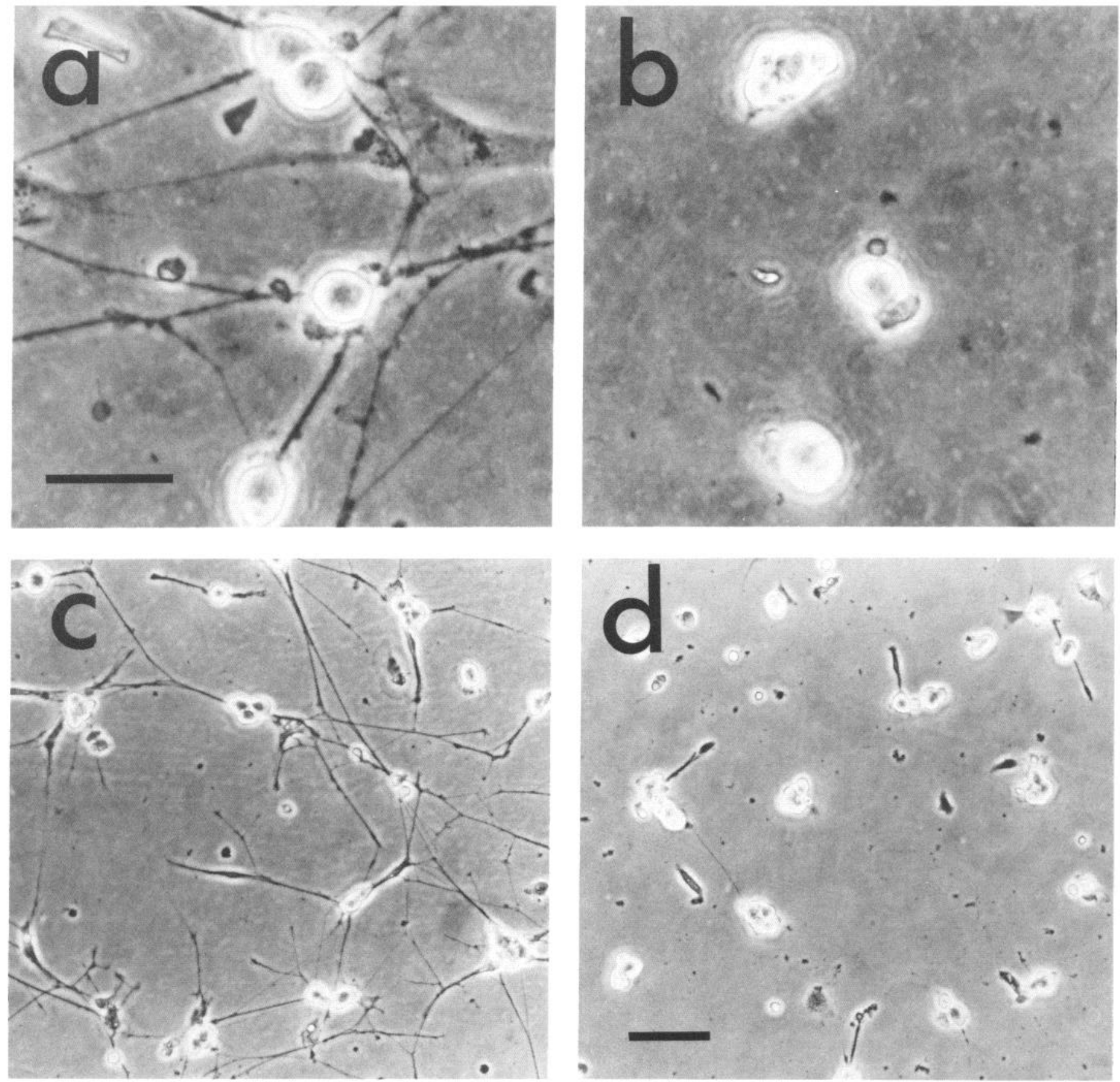

Figure 3. Phase-contrast photomicrographs of dissociated cultures of newborn rat superior cervical ganglia maintained for $1 \mathrm{~d}$ with NGF ( $a$, c) or NGF $+300 \mu \mathrm{M}$ 6-TG $(b, d)$. Panels $a$ and $b$ show high-power views (scale bar, $50 \mu \mathrm{m}$ ), while panels $c$ and $d$ show views at low magnification (scale bar, $100 \mu \mathrm{m}$ ).

\section{Discussion}

Of the several issues addressed by the present work, one was to determine whether the inhibitory effects of purine analogs on NGF-promoted neurite outgrowth by $\mathrm{PC1} 2$ cells also applied to neurons. This is potentially important since a similar sensitivity supports the use of $\mathrm{PC} 12$ cells as an appropriate system in which to further study neuronal effects of the analogs.

Our data demonstrate that the analogs suppressed NGF-dependent neurite growth not only for 2 different classes of neurons, but also in both mammalian and avian systems. Moreover, the dose-response relationships for this inhibition in rat and chick sympathetic neuron cultures were highly similar to one another, as well as to that previously determined for PC1 2 cells (Volonté et al., 1989). This suggests conservation across cell type and species of the $\operatorname{step}(\mathrm{s})$ at which the analogs interfere with NGF action. The dose-response relationships for blockade of neurite outgrowth were also comparable to those with which 6-TG and 2-AP suppress the NGF-elicited induction of ornithine decarboxylase activity in PC12 cell cultures (Volonté et al., 1989). This is consistent with a model in which several diverse actions of NGF can be blocked by the purine analogs 


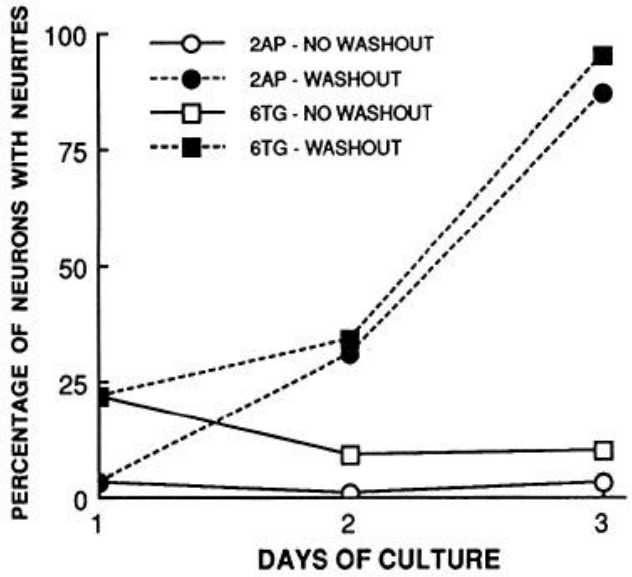

Figure 4. Reversibility of the effects of 6-TG and 2-AP on NGFpromoted neurite outgrowth in dissociated cultures of newborn rat superior cervical ganglia. Pairs of replicate cultures were maintained for $1 \mathrm{~d}$ with NGF and either $300 \mu \mathrm{M}$ 6-TG or $10 \mathrm{~mm}$ 2-AP (values on the $Y$ axis at day 1). After the percentages of neurite-bearing neurons were assessed, the cultures were washed $4 \times$ with culture medium containing neither NGF nor purine analogs. One of each pair was then fed again with medium containing NGF and the appropriate analog (no washout), while the other received only NGF (washout). On days 2 and 3, each culture was rescored for proportion of neurite-bearing neurons. Comparable results were achieved in a replicate experiment.

due to their interference with the same step in the NGF mechanism of action.

A second issue addressed here was whether the pathways by which NGF promotes neurite outgrowth and survival could be distinguished from one another by the use of purine analogs. Our data indicate this to be the case. Although the analogs blocked neurite outgrowth, they did not affect NGF-dependent survival for at least several days. Long-term exposure to the analogs did eventually result in cell death, but this seems more likely to be due to the well-established cytotoxicity of these compounds even in the absence of incorporation into DNA (Elion, 1967) rather than to direct interference with NGF action. Our findings are also consistent with prior evidence that promotion of survival and of neurite outgrowth are mediated by different pathways. Wallace and Johnson (1989) have shown that cytosine arabinoside and related compounds block NGFpromoted survival of cultured sympathetic neurons. However, when a proliferation-blocked population of $\mathrm{PC} 12$ cells was produced by exposure to similar concentrations of cytosine arabinoside in the presence of serum, they retained the capacity to undergo NGF-stimulated generation of neurites, even in the continued presence of the drug (Greene et al., 1982).

Past experiments with $\mathrm{PC} 12$ cells have indicated additional differential effects of purine analogs on NGF actions and thus the presence of at least several distinct pathways in the NGF mechanism (Volonté et al., 1989; Volonté and Greene, 1990). One set of actions is sensitive to both 6-TG and 2-AP (as well as other purine analogs). Thus far, this includes ODC induction and neurite outgrowth. A second set is sensitive to 2-AP, but not to 6-TG. This presently includes the induction of c-fos mRNA and the activation of a distinctive protein kinase (PKN; Rowland et al., 1987). A third category of action appears to be resistant to both 6-TG and 2-AP and includes several rapid NGF-elicited changes in protein phosphorylation. The present findings add promotion of survival to the third set.
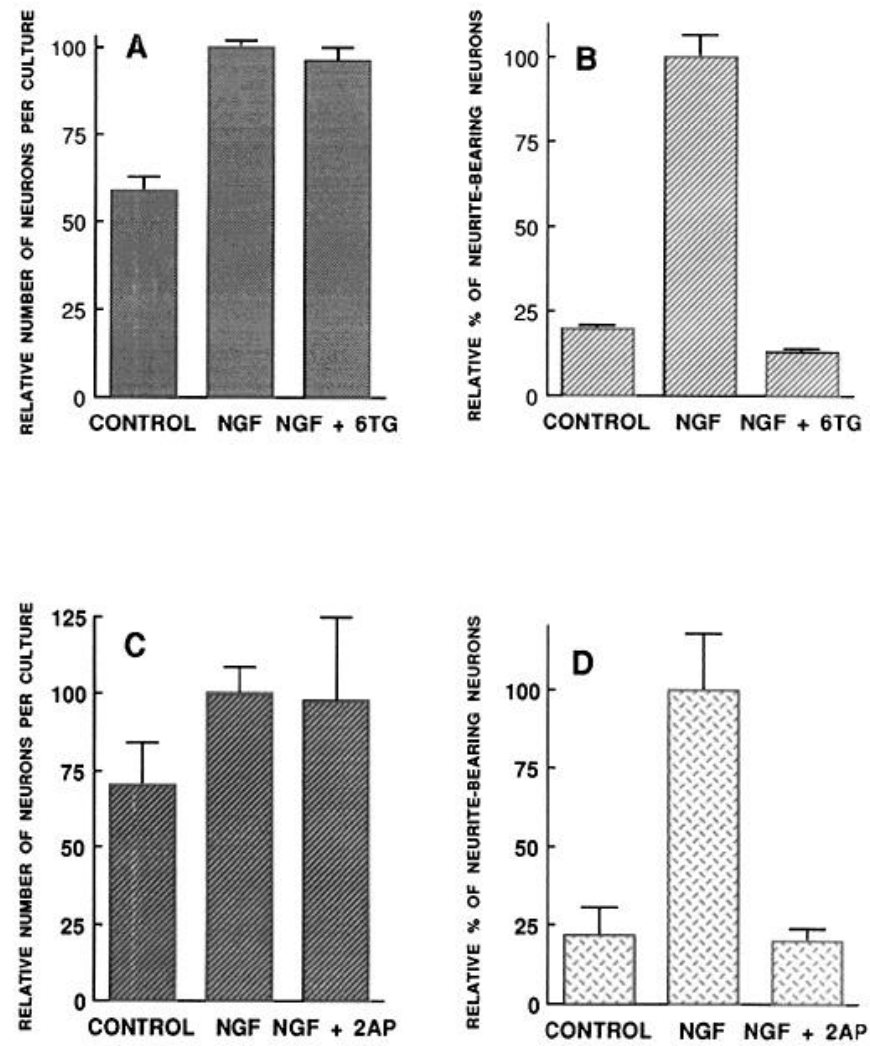

Figure 5. Effects of 6-TG and 2-AP on NGF-promoted neuron survival $(A, C)$ and neurite outgrowth $(B, D)$ in cultures of dissociated newborn rat DRG neurons. Replicate cultures were plated with or without NGF (control) or with NGF and either $300 \mu \mathrm{M} 6-\mathrm{TG}$ or $10 \mathrm{~mm}$ 2-AP. At approximately $24 \mathrm{hr}$ the cultures were assessed for numbers of neurons and proportions of neurons with neurites. Survival data are normalized so that 100 represents the average number of neurons in cultures plated with NGF. For the experiment with 6-TG, this represents 10,666 and for the 2-AP experiment 7963. Neurite outgrowth data are normalized so that 100 represents the average proportion of neuritebearing neurons in cultures plated with NGF. For the 6-TG experiment, this represents $30 \%$ and for the 2 -AP experiment, $34.8 \%$. Values represent averages of determinations on duplicate cultures; error bars indicate range of the duplicate values. Comparable results were achieved in 2 additional experiments with 6-TG and 1 additional experiment with 2-AP.

What might be the common mechanism by which purine analogs promote their differential effects on NGF actions? One attractive hypothesis is via blockade of specific protein kinase activities. There is abundant evidence that the mechanism of action of most growth factors, including NGF, involves the regulation of cellular protein phosphorylation (Halegoua and Patrick, 1980; Yu et al., 1980; Hunter, 1987; Rowland et al., 1987). 2-AP has been shown to be a partially selective inhibitor of protein kinase activities (Farrell et al., 1977; Mahadevan et al., 1989; Volonté et al., 1989). This compound also selectively inhibits the induction of $\beta$-interferon, c-fos and c-myc expression in several cell lines (Zinn et al., 1988). Another analog, 6-dimethylaminopurine, inhibits meiotic maturation of mouse oocytes and appears to do so through interference with protein phosphorylation (Rime et al., 1989). In vitro experiments from our own laboratory (Volonté et al., 1989) have established that purine analogs inhibit a novel NGF-stimulated protein kinase activity designated as PKN (Blenis and Erikson, 1986; Rowland et al., 1987; Rowland and Greene, 1990). Moreover, the dose- 

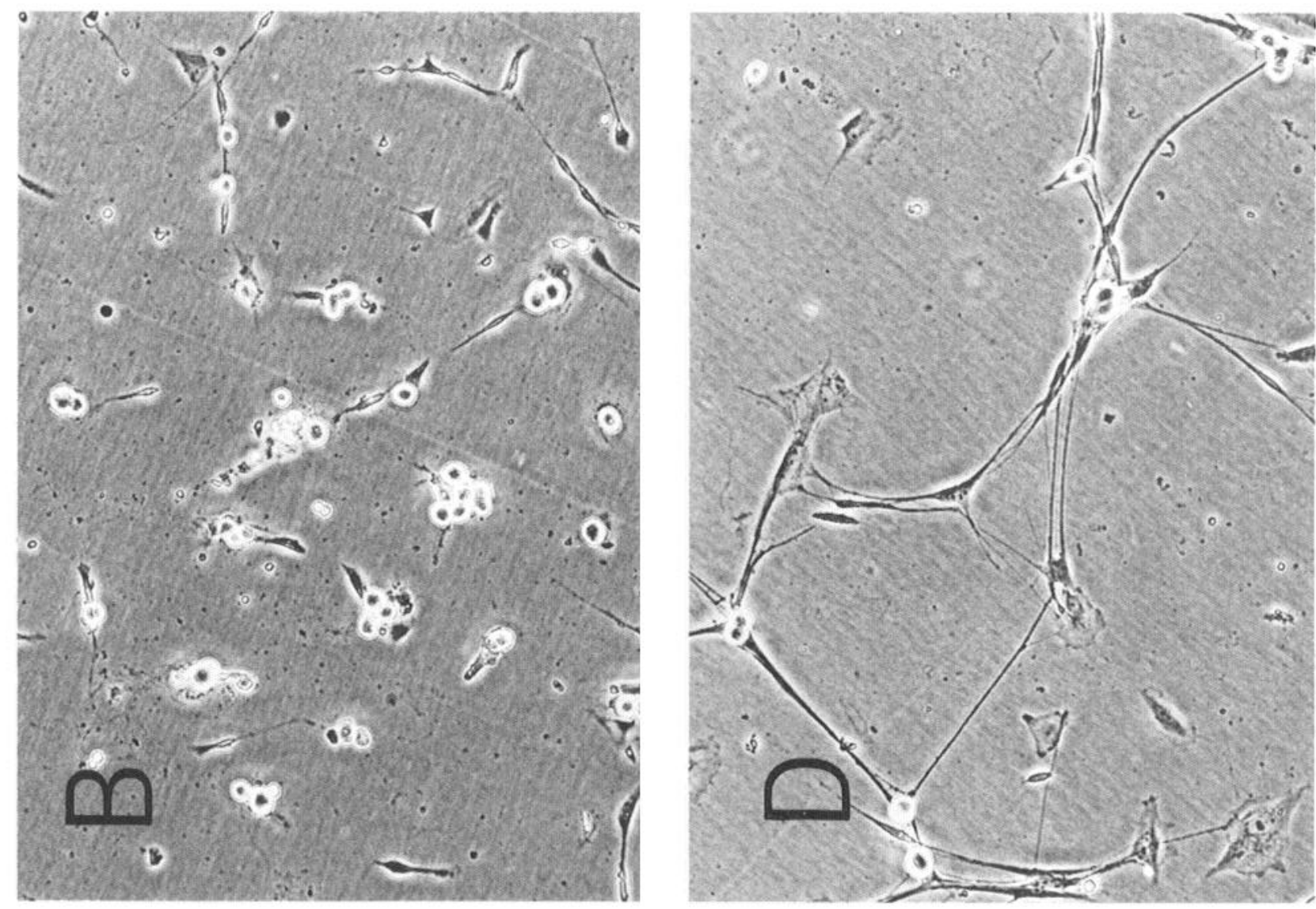

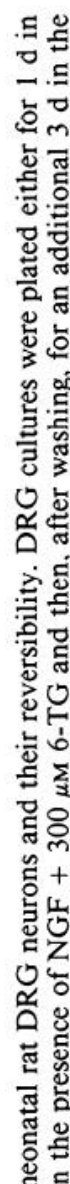
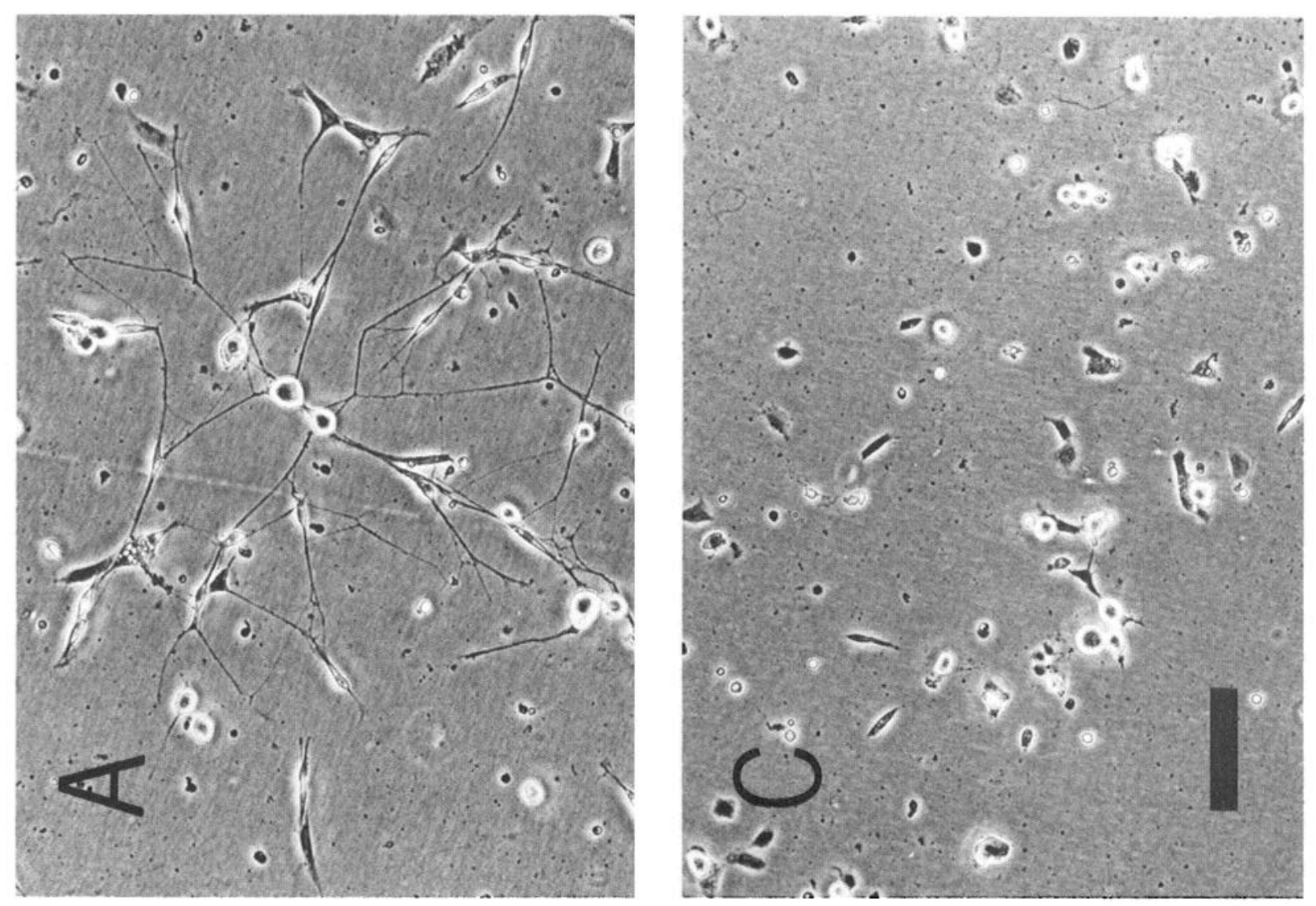

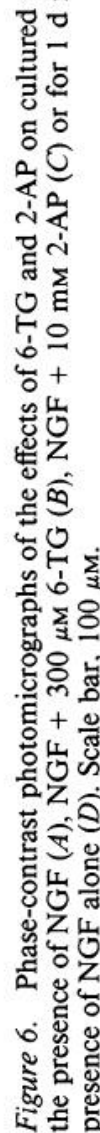



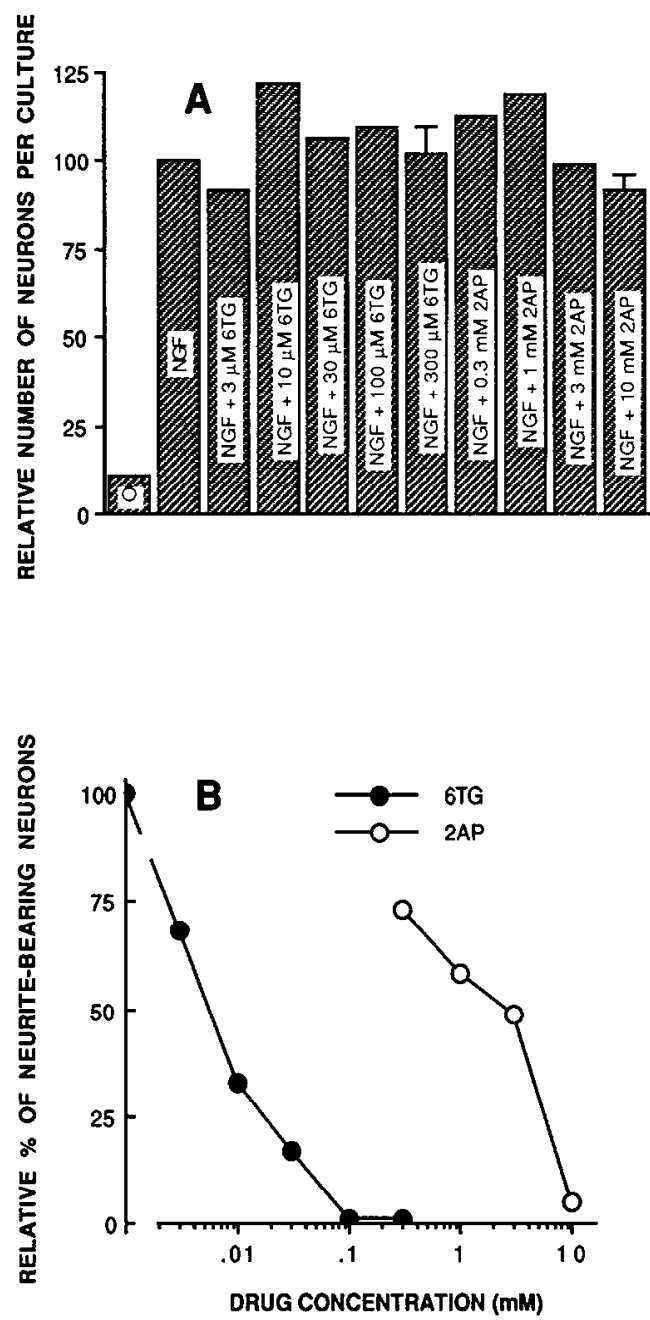

Figure 7. Effect of various concentrations of 6.TG and 2-AP on NGFpromoted survival $(A)$ and neurite outgrowth $(B)$ in dissociated cell cultures of E1 1 chick paravertebral sympathetic ganglia. Replicate cultures were plated with or without NGF as indicated or with NGF and the indicated concentrations of 6-TG or 2-AP. Assessment was at $1 \mathrm{~d}$ after plating. Neuronal number per culture is normalized so that 100 represents the number of neurons in the culture with NGF alone $(25,460)$. The proportion of neurite-bearing neurons is normalized so that 100 represents the percentage of such cells in the culture with NGF alone $(38 \%)$. Values represent those from single cultures except in the cases of $300 \mu \mathrm{M} 6-\mathrm{TG}$ and $10 \mathrm{~mm} 2-\mathrm{AP}$ for which the values are averages from duplicate cultures (error bars show the range).

response relationships for this inhibition are quite close to those with which the same analogs inhibit NGF-stimulated neurite regeneration by $\mathrm{PCl} 2$ cells and neurons and ODC induction in PC1 2 cell cultures. Various types of experiments failed to detect other protein kinase activities that are affected by $6-\mathrm{TG}$, while, by the same criteria, 2-AP appeared to be less selective in this regard (Volonté et al., 1989).

Based on such observations, we have raised the hypothesis that PKN may play a necessary role in certain, but not all, actions of NGF and that the inhibitory effects of purine analogs on NGF action are due, at least in part, to their interference with PKN activity (Volonté et al., 1989). In this scheme, the interaction of NGF with its receptors would initiate a set of kinase-driven pathways, one of which includes PKN activation. The ability of 2-AP to block a wider range of NGF responses than 6-TG would be explained by its lesser specificity as a protein kinase inhibitor. The present data would suggest that neurite outgrowth requires a PKN-dependent event, whereas promotion of survival does not.

\section{References}

Adler, J. E., J. A. Kessler, and I. B. Black (1984) Development and regulation of substance $P$ in sensory neurons in vitro. Dev. Biol. 102: 417-425.

Barde, Y.-A., D. Edgar, and H. Thoenen (1980) Sensory neurons in culture: Changing requirements for survival factors during embryonic development. Proc. Natl. Acad. Sci. USA 77: 1199-1203.

Blenis, J., and R. L. Erikson (1986) Regulation of protein kinase activities in PC12 pheochromocytoma cells. EMBO J. 5: 3441-3447.

Chalazonitis, A., and G. D. Fischbach (1980) Elevated potassium induces morphological diffcrentiation of dorsal root ganglionic neurons in dissociated cell culture. Dev. Biol. 78: 173-183.

Chun, L. L. Y., and P. H. Patterson (1977) Role of nerve growth factor in the development of rat sympathetic neurons in vitro. I. Survival, growth, and differentiation of catecholamine production. J. Cell Biol. 75: 694-704.

Elion, G. B. (1967) Biochemistry and pharmacology of purine analogs. Fed. Proc. 26: 898-904.

Farrell, P. J., K. Balkow, T. Hunt, and R. J. Jackson (1977) Phosphorylation of initiation factor elF-2 and the control of reticulocyte protein synthesis. Cell 11: 187-200.

Greene, L. A. (1977) Quantitative in vitro studies on the nerve growth factor (NGF) requirement of neurons. I. Sympathetic neurons. Dev. Biol. 58: 96-105.

Greene, L. A. (1978) Nerve growth factor prevents the death and stimulates neuronal differentiation of clonal $\mathrm{PCl} 2$ pheochromocytoma cells in serum-free medium. J. Cell Biol. 78: 747-755.

Greene, L. A., and A. S. Tischler (1976) Establishment of a noradrenergic clonal line of rat adrenal pheochromocytoma cells which respond to nerve growth factor. Proc. Natl. Acad. Sci. USA 73: 24242428.

Greene, L. A., D. E. Burstein, and M. M. Black (1982) The role of transcription-dependent priming in nerve growth factor promoted neurite outgrowth. Dev. Biol. 91: 305-316.

Halegoua, S., and J. Patrick (1980) Nerve growth factor mediates phosphorylation of spccific proteins. Cell 22: 571-581.

Hunter, T. (1987) A thousand and one protein kinases. Cell 50:823829.

Lee, V., L. A. Greene, and M. L. Shelanski (1981) Identification of neural and adrenal medullary surface membrane glycoproteins recognized by antisera to cultured rat sympathetic neurons and $\mathrm{PC} 12$ pheochromocytoma cells. Neuroscience 6: 2773-2786.

Levi-Montalcini, R. (1987) The nerve growth factor: 35 years later. EMBO J. 6: 1145-1154.

Levi-Montalcini, R., and P. U. Angeletti (1963) Essential role of the nerve growth factor in the survival and maintenance of dissociated sensory and sympathetic embryonic nerve cells in vitro. Dev. Biol. 7: 653-657.

Mahadevan, L. C., K. Targett, and J. K. Heath (1989) 2-Aminopurine abolishes epidermal growth factor-stimulated phosphorylation of complexed and chromatin-associated forms of a $33 \mathrm{kDa}$ phosphoprotein. Oncogene 4: 699-706.

Rime, H., I. Neant, P. Guerrier, and R. Ozon (1989) 6-Dimethylaminopurine (6-DMAP), a reversible inhibitor of the transition to metaphase during the first meiotic cell division of the mouse oocyte. Dev Biol. 133: 169-179.

Rowland, E. A., T. H. Müller, M. Goldstein, and L. A. Greene (1987) Cell-free detection and characterization of a novel nerve-growth-factor-activated protein kinase in PC12 cells. J. Biol. Chem. 262: 7504 7513.

Rowland-Gagné, E., and L. A. Greene (1990) Multiple pathways of N-kinase activation in PC12 cells. J. Neurochem. 54: 424-433.

Varon, S., C. Raiborn, and E. Tyszka (1973) In vitro studies of dissociated cells from newborn mouse dorsal root ganglia. Brain Res. 54: $51-63$.

Volonté, C., and L. A. Greene (1990) Nerve growth factor (NGF) responses by non-neuronal cells: Detection by assay of a novel NGFactivated protein kinase (PKN). Growth Factors (in press). 
Volonté, C., A. Rukenstein, D. Loeb, and L. A. Greene (1989) Differential inhibition of NGF responses by purine analogues: Correlation with inhibition of an NGF-activated protein kinase. J. Cell Biol. 109: 2395-2403.

Wallace, T. L., and E. M. Johnson, Jr. (1989) Cytosine arabinoside kills postmitotic neurons: Evidence that deoxycytidine may have a role in neuronal survival that is independent of DNA synthesis. $J$. Neurosci. 9: 115-124.
Yu, M. W., N. W. Tolson, and G. Guroff (1980) Increased phosphorylation of specific nuclear proteins in superior cervical ganglia and PC12 cells in response to nerve growth factor. J. Biol. Chem. 255: 10481-10492.

Zinn, K., A. Keller, L.-A. Whittemore, and T. Maniatis (1988) 2 -Aminopurine selectively inhibits the induction of $\beta$-interferon, c-fos, and c-myc gene expression. Science 240: 210-213. 